\title{
Desenvolvimento de modelo físico de simulação espacial em projetos de HIS
}

\author{
Model development to spatial simulation for Social \\ Housing
}

\begin{abstract}
César Imai
Márcio Minto Fabricio

Resumo

A

mais frequente solução adotada para projetos de habitação de interesse social no país é a padronização, que em nome de uma maior racionalidade construtiva e de redução de custos opta pela repetição de uma única solução projetual. No momento em que as características dos usuários não são levadas em consideração no projeto, são comuns adaptações posteriores e reformas dispendiosas e pouco eficientes. O objetivo da presente pesquisa é investigar como as simulações com modelos físicos podem ser uma ferramenta para compreender e atender as demandas dos usuários e auxiliar na implementação de soluções mais adequadas. As simulações ocorreram em um estudo-piloto que visava explorar as potencialidades, características e limitações dos artefatos. Após o exercício de simulação foi aplicado um questionário que abordou questões sobre a compreensão dos usuários de aspectos espaciais e Ifuncionais. Os resultados indicam que os modelos tridimensionais possibilitam melhor entendimento por meio da imersão no ambiente, com melhoria na percepção de questões ergonômicas e espaciais. O maior realismo e a interatividade na simulação na escala real permitem maiores discussões e reflexões sobre o ambiente, que não seriam possíveis em outras formas de representação.

Palavras-chave: Projeto arquitetônico; Habitação de interesse social; Simulação; Avaliação pré-projeto.

Abstract

The usual solution adopted for Social Housing in Brazil is standardisation, which, in the name of constructive rationality and cost reduction, uses the repetition of a single design. When the characteristics of users are not identified in the design process, adaptations and expensive and inefficient reforms are common. The objective of this research study was to investigate how simulations with physical models can be used as a tool to understand and meet the demands of users and

${ }^{1}$ César Imai ${ }^{1}$ Universidade Estadual de Londrina Londrina - PR - Brasil

${ }^{2}$ Márcio Minto Fabricio

¿Universidade de São Paulo São Carlos - SP - Brasil

Recebido em 11/01/19 Aceito em 20/03/19

help the implementation of good solutions. Simulations were done in a pilot study that explored the potentials, characteristics and limitations of the models. After the simulations, a questionnaire was applied focusing on users' understanding of spatial and functional issues. The results indicate that three-dimensional models allow a better understanding of the immersion in the environment, with improved perception of ergonomic and spatial issues. Greater realism and interactivity in the real-scale simulation allow for more discussions and reflections about the environment, which would not be possible in another type of representation.

Keywords: Architectural design. Social Housing. Simulation. Pre-Design Research.
\end{abstract}




\section{Introdução}

A abordagem do problema do projeto é, por vezes, variável conforme as condicionantes da época e do contexto no qual o objeto será inserido. No entanto, ainda que a forma de tratar a questão seja diferente de acordo com as condições, as abordagens dos projetistas já foram sistematicamente estudadas e buscou-se analisar os seus procedimentos para compreender melhor esse processo (LAWSON, 2011). No caso brasileiro das habitações de interesse social produzidas nas últimas décadas, é sintomático que os projetos dessas habitações possuem pouca ou nenhuma evolução nas discussões sobre sua qualidade funcional e ambiental. Sem dúvida, podemos discutir se ocorreram melhorias derivadas de um melhor controle dos gestores públicos na aplicação de novas normas ou na adoção de tecnologias construtivas inovadoras. A forma de conceber o projeto, no entanto, fica focada no maior aproveitamento e na viabilidade financeira para as empresas construtoras, induzidas e conformadas por regras e legislações que permitem maximizar a viabilidade do empreendimento pela minimização das dimensões e espaços. Algumas regras de dimensionamento ambiental e de utilização de parâmetros dimensionais de móveis e equipamentos foram adequadas enquanto propostas, porém insuficientes em sua abrangência para encarar o problema de forma mais sistêmica.

Uma das soluções adotadas em diversos projetos nas últimas décadas é a sua padronização, que em nome de uma maior racionalidade construtiva, pela repetição de uma única solução projetual, permitiria reduzir custos na implantação e manutenção dessas edificações. Essa premissa, no entanto, é relativamente derivada da comodidade em utilizar um modelo de produção que funcione para o agente produtor (construtora), para o agente financiador (banco) e para o poder público, que patrocina e incentiva a implantação de conjuntos massificados pela padronização, propondo um atendimento para todo o conjunto da população que, apesar de sua diversidade, é considerada como homogênea apenas por possuir baixa renda. Muitas discussões podem ser feitas sobre quanto o objetivo de reduzir o déficit habitacional ficou permeado por outros objetivos, como ativar e impulsionar a economia por meio de uma ampla produção na indústria da construção civil ou mesmo para auferir capital político pela entrega de moradias ao maior número de pessoas possível, ainda que a qualidade funcional e dimensional do projeto possa ser questionada. Essas questões são válidas e pertinentes, porém o foco dessa pesquisa está nas questões funcionais do projeto e, especificamente, da unidade habitacional.

Diversas pesquisas estudam há décadas o problema projetual pela abordagem de um maior aprofundamento nas questões de contexto sob o ponto de vista das demandas e requisitos dos usuários que utilizam esses ambientes. A área da avaliação pós-ocupação (APO) possui diversas pesquisas que buscaram durante anos compreender as diversas questões e problemas que permeiam, não apenas os aspectos construtivos dessa produção habitacional, mas também os aspectos comportamentais que afetam, em última instância, a percepção da qualidade ambiental. Não é razoável supor que diferentes grupos familiares, com variadas demandas, possam se adequar a um mesmo padrão de projeto, considerando que esse modelo adota o menor dimensionamento possível, normalmente sem planejamento ou abordagem do aspecto de flexibilidade.

Ainda que essas pesquisas tenham produzido uma quantidade de informações que permitam compreender melhor os usuários, com suas demandas e aspectos comportamentais, esse conhecimento pouco é aplicado na definição do projeto. No momento em que essas características não são claramente delimitadas nas etapas préprojetuais e, consequentemente, não são implementadas no projeto final, são comuns adaptações e reformas dispendiosas e pouco eficientes, pois não foram consideradas na elaboração do projeto. Esse aspecto é particularmente perverso, pois acarreta um duplo desperdício de recursos e esforços quando a edificação recém-construída, em pouco tempo, passa por alterações para atender as necessidades de seus moradores. Dessa forma, o poder público investe recursos por meio de subsídios na implementação das moradias e os moradores gastam novamente em reformas não planejadas, que nem sempre são positivas em relação à qualidade final do ambiente.

A participação dos usuários nas definições do projeto da habitação pode trazer significativas contribuições ao levar em consideração a experiência do morar e as demandas subjetivas de cada grupo. O envolvimento dos usuários pode permitir uma maior apropriação do ambiente projetado tanto nos seus aspectos funcionais quanto nas questões subjetivas e afetivas.

Diversas experiências foram aplicadas a partir dos anos 1950 em nível internacional sob a ótica de permitir maior participação de futuros usuários na elaboração ou na definição de seus projetos. Essas experiências buscavam que os projetistas aplicassem teorias de democracia participativa ao permitir maior poder de decisão aos futuros moradores, não apenas como um processo de consulta e coleta de informações, mas focando nas inter-relações entre os indivíduos e nas estruturas de autoridade das instituições. Essa descentralização do 
processo, por meio de uma busca de informações coletivas, ainda que mais complexa, pode ser considerada como um caminho para evitar problemas funcionais de projeto derivados de inadequações diversas.

O processo de projeto com uma abordagem centrada no usuário muda a forma de encarar os papéis do projetista e do usuário. Isso demanda uma abordagem dos projetistas com o foco na pesquisa, com uma nova forma de encarar o processo e com mudanças na própria formação dos profissionais (SANDERS; STAPPERS, 2008). Essas abordagens de aproximação entre os projetistas e os futuros usuários dos espaços tornam-se cada vez mais relevantes a partir das mudanças da sociedade que demandam novas necessidades e tecnologias em uma velocidade cada vez maior. $\mathrm{O}$ valor passa a ser atribuído não apenas por conceitos consolidados, mas também por abordagens que definam o produto com base no que as pessoas precisam. Nesse sentido, o usuário passa a ser considerado não como uma meta de atendimento final, mas como um "parceiro" que pode gerar informações valiosas sobre os conceitos dos produtos que foram gerados por outras pessoas (SANDERS; STAPPERS, 2008). Essas informações podem ser geradas tanto na análise e avaliação de um produto em uso, quanto nas etapas prévias de planejamento envolvendo o próprio usuário.

Em uma perspectiva mais tradicional, os requisitos do usuário são geralmente identificados ou delimitados por projetistas ou programadores que irão desenvolver as etapas iniciais do projeto. A coleta de dados necessária para identificar demandas é feita por entrevistas ou reuniões com especialistas dos sistemas do edifício. Segundo Jensen, Alexander e Fronczek-Munter (2011), o envolvimento do usuário nesse processo é peça fundamental para permitir um processo mais interativo, o que evitaria diversas limitações dos procedimentos, fazendo com que os projetistas liderassem conversações e diálogos com os usuários ou seus representantes. Uma das formas de interação com os usuários nas etapas iniciais do projeto para coleta de informações pode ser empregada por um conjunto de métodos e técnicas conhecido como avaliação préprojeto (APP). Em linhas gerais, a APP utiliza ferramentas consagradas em pesquisas comportamentais, notadamente empregadas em avaliações pós-ocupação, tais como entrevistas, questionários e dinâmicas em grupos focais, por exemplo. Esses instrumentos podem ser aplicados em diversos tipos de pesquisa e possuem eficácia comprovada e bem delimitada. Outras formas de discutir ou apresentar questões de projeto, no entanto, são mais adequadas para explorar aspectos do ambiente que ainda não foi construído, e às vezes nem mesmo planejado, estando ainda no campo das ideias prévias e da delimitação do problema de projeto a ser resolvido. Nesse sentido, a elaboração de desenhos, modelos, simulações e protótipos pode contribuir para o entendimento do objeto, não apenas em um ciclo fechado para o próprio projetista, mas também para a comunicação entre os diversos agentes intervenientes no processo projetual, entre os quais podemos destacar os potenciais futuros usuários.

Nas etapas prévias ou iniciais do projeto, uma das dificuldades para a melhor compreensão das características e necessidades das pessoas está na comunicação entre projetista e usuário, pois muitas vezes a linguagem empregada para representar e comunicar o projeto pode causar interpretações equivocadas por uma parte dos leigos não acostumados com as peças gráficas.

Segundo Malard (2002), as diferenças de compreensão entre o mundo imaginado e o mundo real deveriam gerar a meta de que o leigo tenha meios de acessar esses códigos de representação para que possa contribuir com a proposição. Se não for dessa forma, o processo participativo seria apenas uma manipulação para legitimar as decisões tomadas pelos técnicos.

Segundo Sanders (2013), em um processo de projeto mais atual é necessário que os meios de simular os futuros objetos não sejam apenas representações, mas ferramentas de exploração coletiva, expressando e testando hipóteses sobre formas contemporâneas de vivenciar o mundo. Na busca pela virtualidade de um ambiente no projeto, essa exploração coletiva demanda formas de apresentá-lo de uma maneira didática para todos os participantes da avaliação. Como os usuários leigos possuem diferentes níveis de capacidade de abstração e de conhecimento prévio, nem todos terão a mesma facilidade de compreensão de uma representação gráfica tradicional (IMAI; AZUMA, 2015; IMAI et al, 2015).

A representação que torna o objeto mais próximo ao universo de conhecimento das pessoas é a melhor forma para tornar esse objeto mais inteligível para um grupo não técnico e heterogêneo. Nesse sentido, a representação tridimensional do projeto traz vantagens no entendimento global da edificação, observando que deve ser complementada com desenhos tradicionais bidimensionais. A forma de comunicação que torna o objeto mais próximo do real facilita a correlação entre a representação e o conhecimento prévio das pessoas.

A simulação é uma forma de investigação projetual que pode ser aplicada com procedimentos de representação convencional em estratégias combinadas. Nesse sentido, permite produzir conhecimento sobre possíveis condições do mundo real sem ultrapassar as barreiras éticas, os perigos físicos ou as despesas financeiras quando executamos um ambiente real (WANG, 2013). Apesar da limitação do caráter reducionista da 
simulação, que não possibilita prever com exatidão o comportamento futuro e as possíveis variáveis mais complexas, ainda assim o procedimento pode contribuir para uma melhor compreensão de padrões de comportamento atuais ou expectativas de comportamentos futuros.

Em relação às ferramentas utilizadas na simulação, diversas pesquisas apontam as potencialidades e os benefícios dos modelos tridimensionais na exploração do desenvolvimento e da apresentação de ideias (CELANI et al, 2009; PINA; BORGES FILHO; MARANGONI, 2011; IMAI; AZUMA, 2009; entre outras). Groat e Wang (2013) destacam que a ferramenta tridimensional possibilita a análise das variáveis projetuais e a previsão das consequências de decisões programáticas. Assim, as simulações tridimensionais podem auxiliar em uma participação efetiva do usuário nas definições projetuais, algo que Sanoff (2000; 2006a; 2006b) sempre colocou como fundamental para democratização das ideias no processo de projeto.

As simulações podem empregar modelos digitais ou físicos, que possuem diferenças na sua execução, mas que em linhas gerais buscam atingir o mesmo objetivo de antever possibilidades e explorar alternativas de forma mais simplificada do que a concretização de um objeto real. O foco na comunicação com o usuário leigo busca permitir uma melhor compreensão do projeto e uma comunicação que permita adotar linguagem compreensível a todos os envolvidos.

A utilização de modelos tridimensionais físicos e digitais para comunicação com o usuário deve ser feita levando em consideração as diferenças entre os grupos de futuros moradores e explorando possíveis interfaces com representações digitais. Esses procedimentos podem auxiliar na verificação de como as escolhas no modelo físico influenciam os custos decorrentes dessas opções de projeto.

A presente pesquisa aborda o modelo físico como um instrumento de comunicação em variadas fases, como na interface com modelos reduzidos e nas suas simulações. Ainda que a redução de informações constantes em um modelo seja natural e esperada, para simplificar o processo de manipulação e compreensão do objeto em si, a proposta da pesquisa prevê adotar diferentes escalas de detalhe, permitindo complementações de informações desde a percepção do conjunto ao detalhe da utilização do espaço. Nesse sentido, foram adotados modelos físicos em diversas escalas para estudar a execução e o funcionamento de um protótipo de simulação física de ambientes em escala real. Após a finalização desse artefato, foi aplicado um estudo-piloto de simulação para testar as potencialidades de seu uso com modelos em escala reduzida de simulação de ambientes habitacionais.

O objetivo geral da pesquisa foi desenvolver um modelo físico reconfigurável em escala real que combinado a modelos em escala reduzida pudessem contribuir para o processo de comunicação entre o projetista e o usuário no desenvolvimento de programas e projetos de HIS.

Buscou-se investigar como as simulações com modelos tridimensionais ajustáveis (em escala real e escala reduzida) podem ser uma ferramenta para compreender o objeto a ser construído, bem como facilitar o diálogo entre o projetista e demais participantes do processo de projeto, incluindo o usuário leigo. A pesquisa busca particularmente entender as potencialidades comunicativas do modelo em escala real, a compreensão de aspectos funcionais dos ambientes por meio desse instrumento e seus possíveis impactos em metodologias de projeto de HIS.

\section{Delineamento da pesquisa}

A presente pesquisa tem um caráter propositivo e de desenvolvimento de soluções inovadoras de interação entre projetistas e usuários e foi desenvolvida através da abordagem da design science research (DSR), conforme explicitado na Figura 1, que descreve as etapas da pesquisa.

Para Dresch, Lacerda e Antunes Junior (2015, p. 67) design science research tem como principal objetivo desenvolver um artefato ou uma prescrição, sendo, portanto, um método de pesquisa orientado para a solução de problemas, pois " [...] a design science research busca, a partir do entendimento do problema, construir e avaliar artefatos que permitam transformar situações, alterando suas condições para estados melhores ou desejáveis [...]”.

O problema investigado foi a efetividade na comunicação entre projetistas e usuários em processos participativos para customização de projetos de unidades habitacionais em empreendimentos de HIS.

A partir de outros estudos prévios dos autores (IMAI, 2010; IMAI et al., 2015) foi aceito como pressuposto que modelos físicos tridimensionais configuráveis possibilitam fácil interação e compreensão compartilhada de aspectos espaciais entre projetistas e usuários. Os modelos físicos estudados na literatura foram todos desenvolvidos em escala reduzida e o questionamento que motivou a pesquisa e o desenvolvimento do artefato 
proposto foi que os modelos físicos em escala real permitiriam, em tese, a compreensão mais efetiva pelo usuário de aspectos relacionados a dimensão real dos ambientes, funcionalidade e ergonomia do arranjo espacial de diferentes ocupações com móveis e equipamentos.

Para garantir a viabilidade do seu emprego em processos participativos de projeto de HIS, o desenvolvimento do modelo em escala real (artefato proposto) deveria ser flexível para permitir reconfigurar facilmente os ambientes simulados, manter a leveza das peças e estruturas para permitir o transporte e armazenamento e ser relativamente barato.

No desenvolvimento do artefato foram utilizadas diferentes técnicas de projeto auxiliado por computador, testes de soluções em escala reduzida e em escala real. Depois de consolidado o projeto do modelo, o artefato foi construído e testado em laboratório para verificar sua resistência, funcionalidade e facilidade de configuração de diferentes arranjos espaciais e facilidade de montagem e desmontagem.

Por fim, foi realizado uma avaliação preliminar do modelo em simulações realizadas com os alunos de uma disciplina de projeto de HIS em nível de pós-graduação. Na disciplina os alunos foram estimulados a utilizarem modelos em diferentes escalas (1:10, 1:20 e real) para simulações ambientais no início do processo de projeto. Posteriormente, os alunos participantes foram questionados sobre as vantagens, as desvantagens, os limites e as dificuldades no uso dos diversos modelos físicos disponibilizados.

\section{Figura 1 - Encadeamento lógico e etapas da pesquisa}

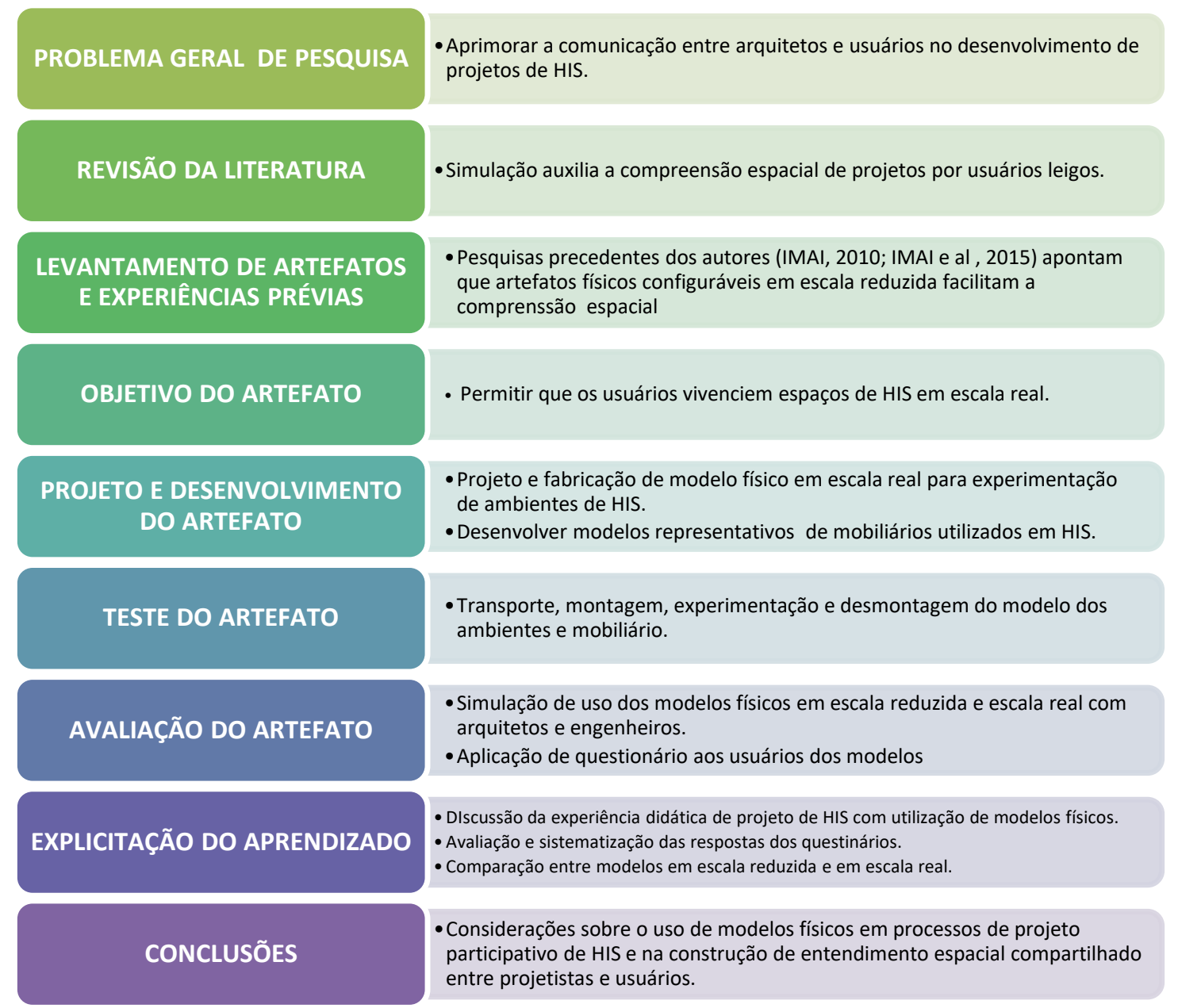




\section{Desenvolvimento do artefato}

Na primeira etapa da pesquisa foram desenvolvidos estudos para verificar a formatação do modelo em escala real, tomando como ponto de partida os modelos em escala reduzida empregados em pesquisas anteriores (IMAI, 2010; AZUMA, 2016; RODRIGUES, 2016; ZALITE, 2016). A ideia original de desenvolver um protótipo em escala real partiu de alguns requisitos que determinaram o planejamento de sua execução. A concepção de que o projeto arquitetônico seria desenvolvido de forma mais adequada para os futuros usuários se eles pudessem participar na definição de aspectos programáticos do projeto, com as devidas limitações que a temática demanda, parte da premissa de que o artefato necessita não apenas ser didático em seu aspecto comunicativo, mas também de fácil maneabilidade e que possa ser aplicado em diferentes condições e locais. Essas condicionantes devem prever que, por vezes, o artefato permita o exercício projetual da simulação indo até o grupo de usuários, como em conjuntos habitacionais ou companhias de habitação, e não estando fixo em algum local específico. Essa “ida” até o usuário demanda que seja facilmente montado e desmontado, de forma relativamente rápida e sem grandes necessidades de estrutura ou de ambiente físico, com dimensões relativamente fáceis para transporte em qualquer veículo utilitário.

Delimitadas essas condições, o planejamento partiu da definição de quais aspectos seriam necessários ou possíveis simular em um ambiente em escala real. Como a ideia original dos modelos em escala reduzida era simular habitações de interesse social que permitissem realizar alterações de projeto em tempo real e de forma ágil, as peças que simulam as paredes foram planejadas para serem móveis, permitindo uma mudança de seu posicionamento, aumentando ou diminuindo cada ambiente. Os modelos reduzidos também permitiam alterar posicionamento de vãos e aberturas, bem como alterar os leiautes dos ambientes modificando o posicionamento de móveis e equipamentos (Figura 2).

Como os modelos reduzidos originais estavam em escalas como 1:20 e 1:10, o planejamento inicial partiu de novas execuções de modelos em escalas maiores. Em um primeiro estudo, partindo da condicionante de transporte, buscou-se desenvolver o modelo em módulos que simulassem ambientes com dimensões máximas de 3,5 m por 3,5 m, de tal forma que pudessem ser desmontados e dobrados em dimensões máximas de aproximadamente 1,75 m de comprimento. A ideia inicial foi a de simular variações dos ambientes da sala e da cozinha de uma habitação social projetados de forma conjunta (cozinha americana) ou separadamente. A simulação das paredes se deu por meio de lonas plásticas fixadas em estruturas móveis (pontes) que permitem ampliar ou diminuir o tamanho dos ambientes em um sistema de trilhos e rodízios. Outro aspecto observado foi o peso final da estrutura, suficientemente leve para transporte e razoavelmente rígido para garantir sua estabilidade. A opção inicial foi a adoção de peças treliçadas relativamente esbeltas para diminuir seu peso próprio. Foi executado um modelo tridimensional em acrílico na escala 1:4 para estudar as possibilidades de utilização do protótipo (Figura 3). O modelo também permitiu antever possíveis problemas de estabilidade e estudar formas de reforço da estrutura que não prejudicassem o processo de simulação. Por meio da observação no modelo foram propostas estruturas de mão-francesa e barras de contraventamento, bem como variações de apoio das pontes móveis e de seu dimensionamento.

\section{Figura 2 - Modelos físicos alteráveis para desenvolvimento do projeto de HIS}
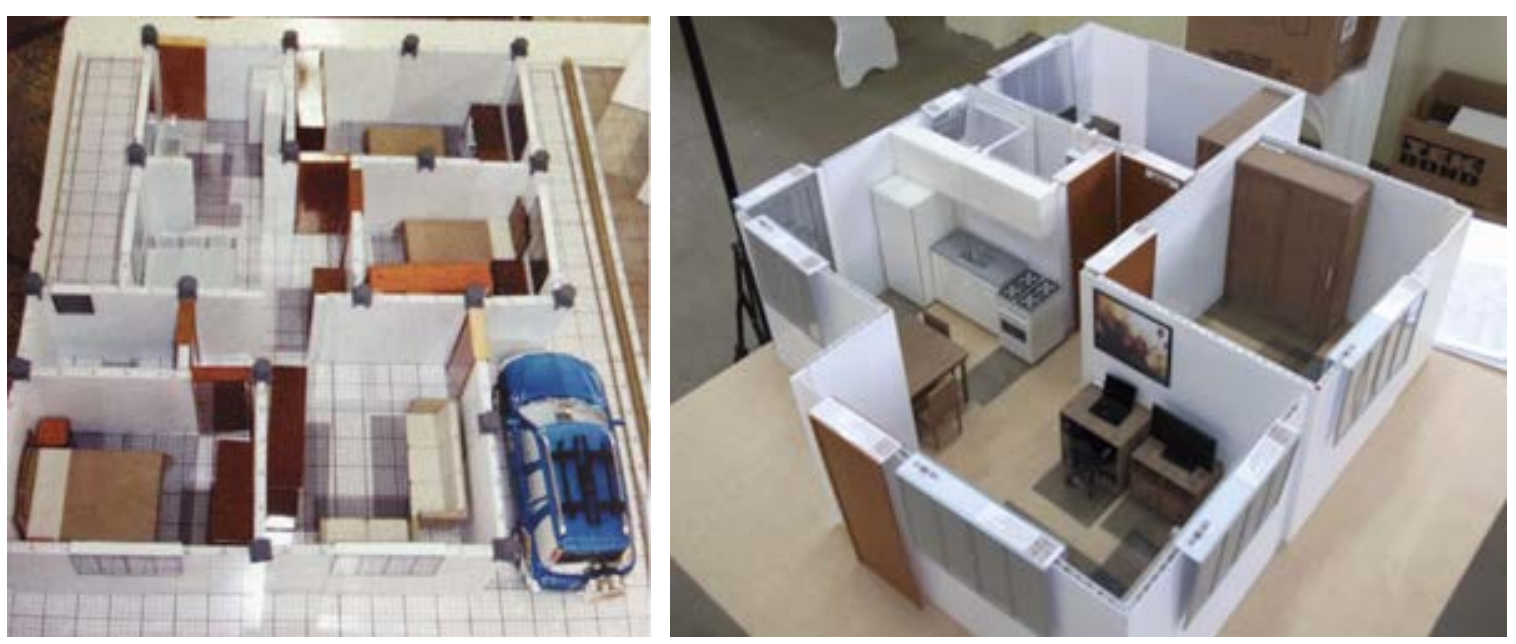

Fontes: Imai (2010, p. 80) e Zalite (2016, p. 81). 


\section{Figura 3 - Modelo na escala 1:4 em acrílico simulando três módulos e vedações}
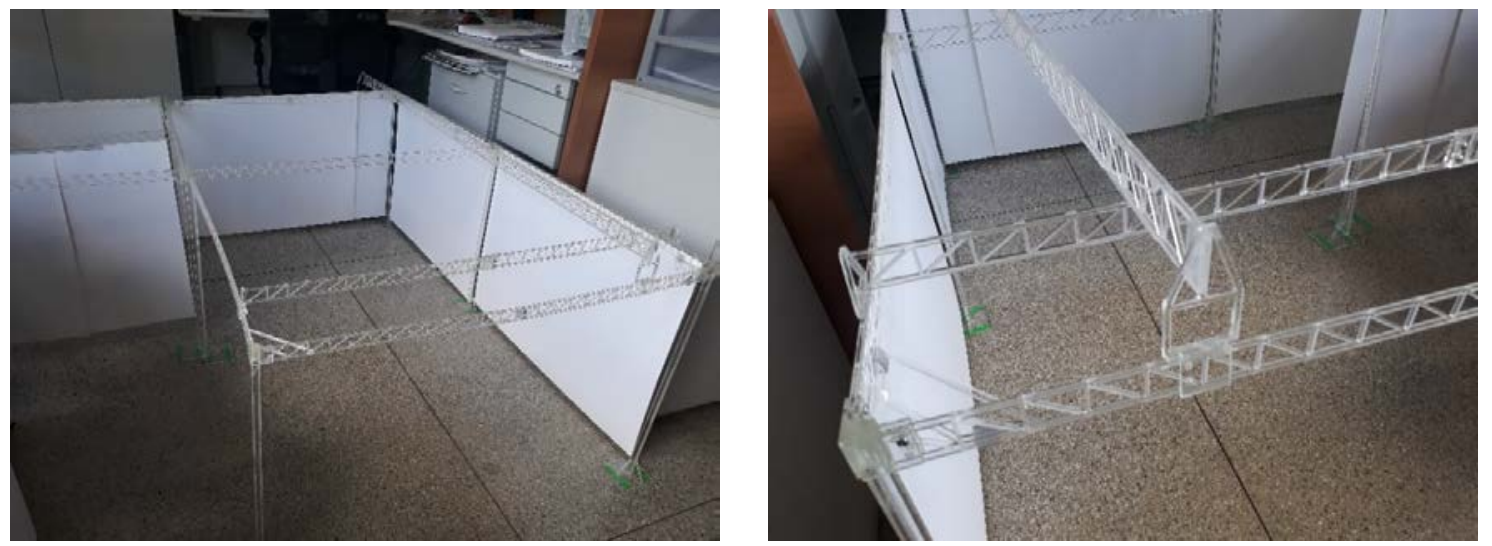

Após essa etapa foram desenvolvidos modelos de partes da estrutura em escala 1:1 em MDF para verificar alguns aspectos construtivos e de funcionamento da estrutura, como junções das peças verticais com as vigas treliçadas e detalhes de desenho das pontes e do sistema de rodízio que iriam permitir o deslizamento da estrutura metálica da ponte na qual as lonas plásticas que simulam as paredes estariam fixadas em trilhos (Figuras 4 e 5).

Esses modelos em escala real foram importantes para simular como as pontes metálicas seriam apoiadas nas vigas metálicas treliçadas que formam a base do modulo de $3,5 \mathrm{~m}$ por 3,5 m. Foram simuladas as possibilidades de apoio superior e lateral na viga (Figura 6). A solução no protótipo foi uma mescla das duas situações, em que foi desenvolvido um sistema de rodízio com duplo apoio (Figura 7). Essa solução foi adotada para garantir maior estabilidade e evitar quedas ou a ponte deslocar ou sair dos trilhos.

Após a execução da estrutura foi identificada uma série de aspectos em seu funcionamento que poderiam ser modificados no intuito de simplificar formas de encaixe nas estruturas desmontáveis, reduzindo a quantidade de peças e simplificando o seu desenho. Vale ressaltar que esses aprimoramentos tinham por objetivo melhorar detalhes e reduzir custos em sua execução sem alterar substancialmente a sua mecânica funcional. Essas alterações somente foram possíveis após a execução da primeira versão da estrutura final. Após a sua execução foram feitas simulações de seu uso e explorados aspectos de sua movimentação. Esses aspectos serão descritos nos resultados e nas discussões.

A elaboração dos móveis e equipamentos a serem empregados nas simulações também partiu dos mesmos princípios adotados na estrutura de simulação das paredes e aberturas. As peças deveriam ser leves o suficiente para permitir a sua rápida e fácil movimentação e deslocamento no ambiente a ser simulado, explorando de forma ágil diferentes alternativas de leiaute. Também deveriam ser facilmente desmontáveis (e posteriormente remontadas) para permitir seu transporte em pequenos veículos (Figura 8). Para explorar as possibilidades e eventuais dificuldades foram elaborados modelos em papel cartão de diferentes móveis habitacionais na escala 1:3. A experiência dos modelos anteriores indicou a utilidade de executar o protótipo mais próximo à escala real para permitir antever aspectos construtivos, estruturais e de funcionamento, conforme será descrito nos resultados.

Alguns testes foram feitos como estudo-piloto na execução dos móveis na escala 1:1 e foram executados em papelão micro-ondulado nos princípios básicos planejados nos modelos na escala 1:3 (Figura 9). Posteriormente, devido a aspectos de fragilidade na armazenagem e no transporte, optou-se por desenvolver os móveis e equipamentos finais em chapas plásticas tipo “polionda” (Figura 10).

Foram desenvolvidos módulos da estrutura final, de 3,5 m por 3,5 m, que poderiam ser dispostos individualmente ou sequencialmente em dois ou três módulos e eventualmente em formato de L. Foram executados diversos móveis para uma moradia, tais como fogão, geladeira, pia, armários diversos, mesa, sofás e móvel para apoio de televisão. As simulações tiveram diferentes alternativas de leiaute e de dimensão de uma sala conjugada com cozinha, partindo de formatos usualmente utilizados em soluções de projeto de HIS (Figura 11).

Após a definição do protótipo, o planejamento da simulação foi desenvolvido para a aplicação de um estudopiloto que visava explorar as potencialidades, características e limitações do artefato. Optou-se por realizar o exercício na área de uma habitação composta por sala e cozinha devido à maior variedade de atividades nesses 
ambientes e por geralmente possuírem dimensões diminutas nos projetos de HIS. Para demonstrar o conjunto da habitação, a opção foi complementar a simulação em escala real com modelos reduzidos nas escalas 1:20 e 1:10, e com desenhos de leiaute das respectivas soluções em planta.

\section{Figura 4 - Detalhes do modelo em escala 1:1 - encaixe viga/pilar}
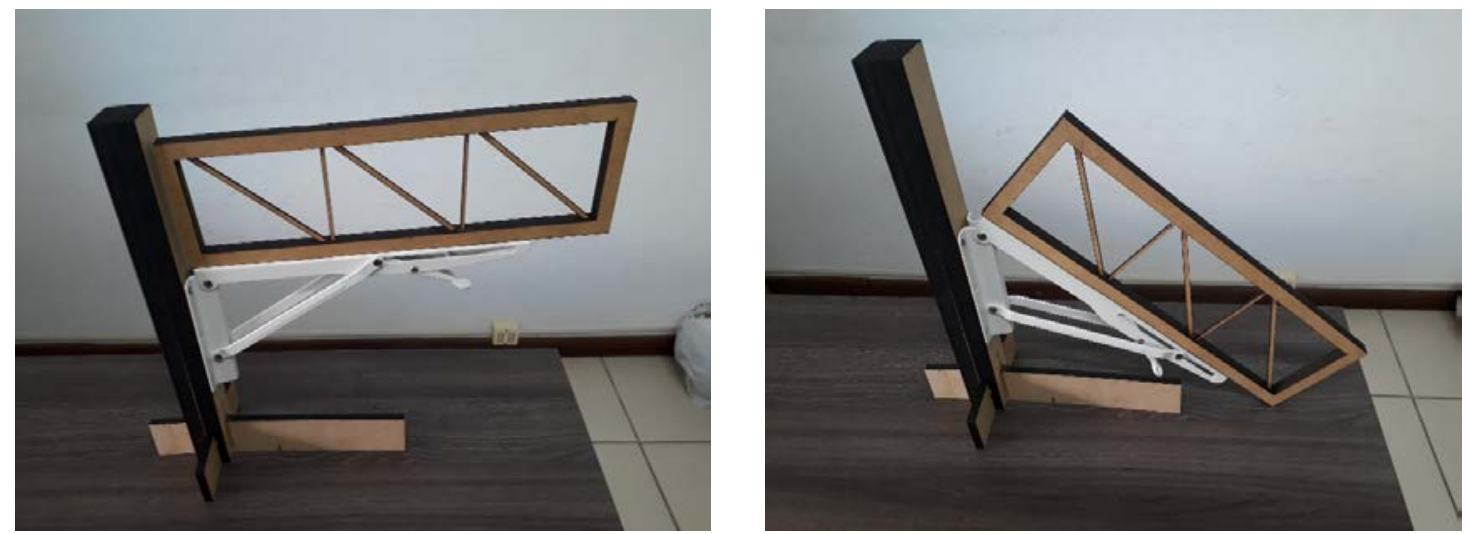

Figura 5 - Detalhes do modelo em escala 1:1 - ponte
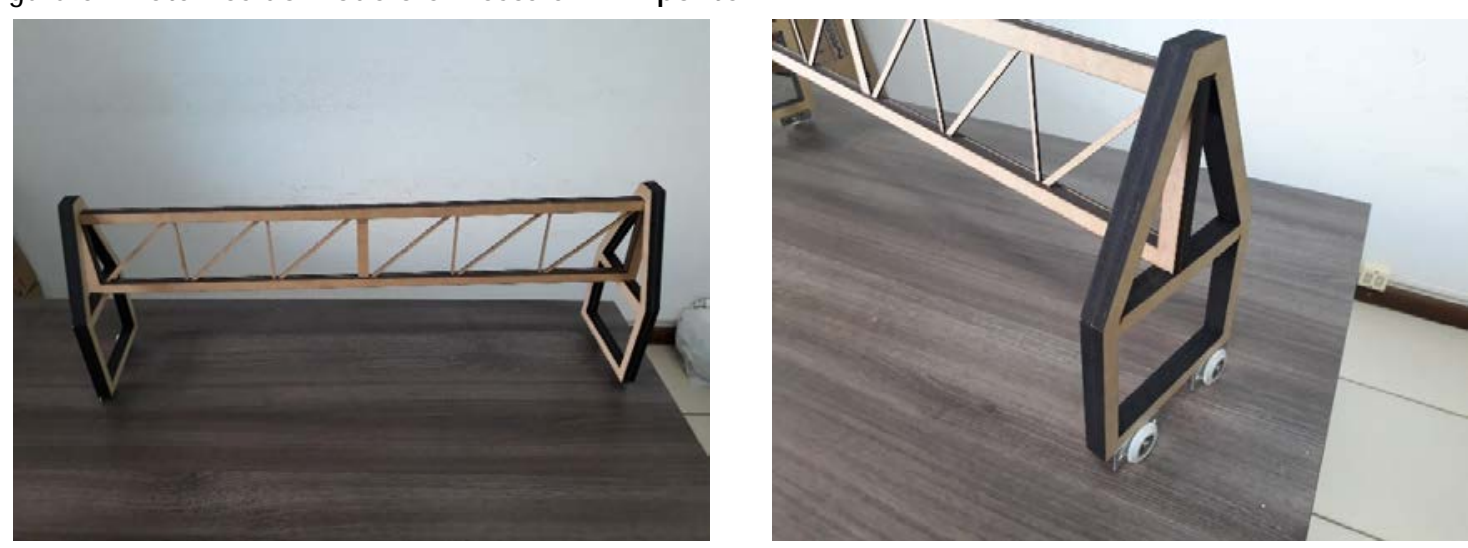

Figura 6 - Detalhes de apoio da ponte
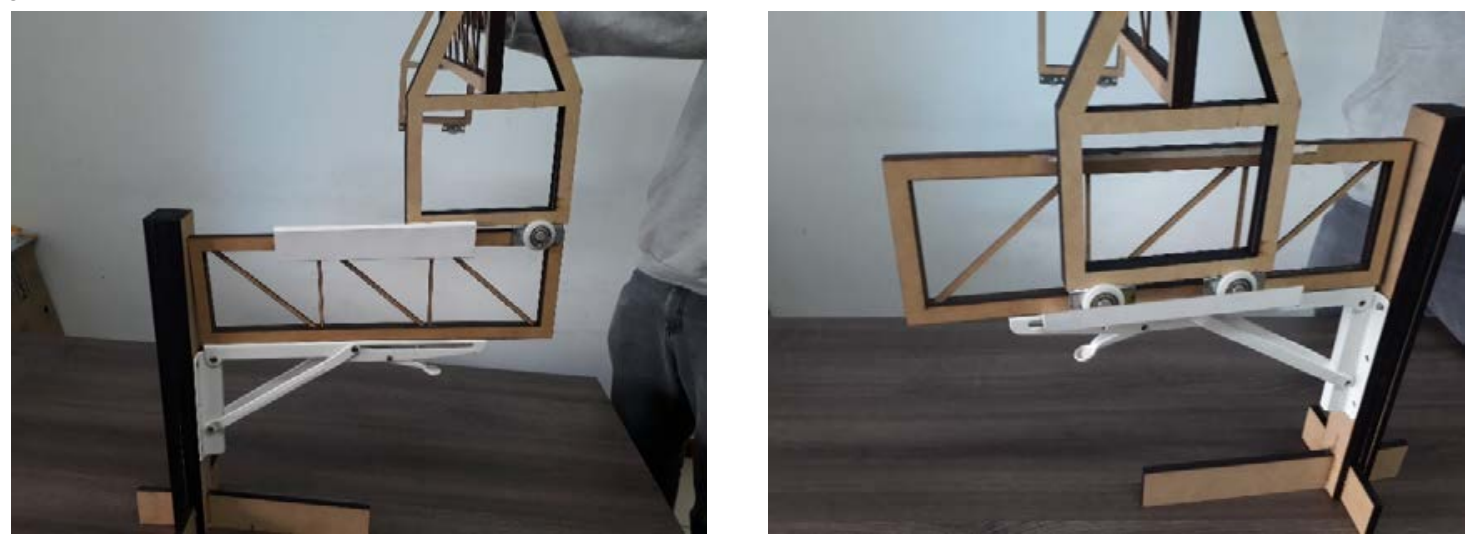
Figura 7 - Sistema de rodízio duplo do protótipo

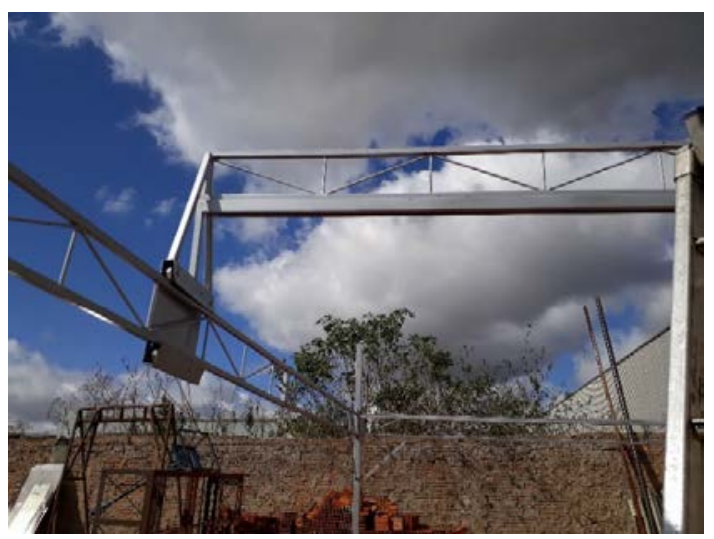

Figura 8 - Sistema de montagem e desmontagem do móvel
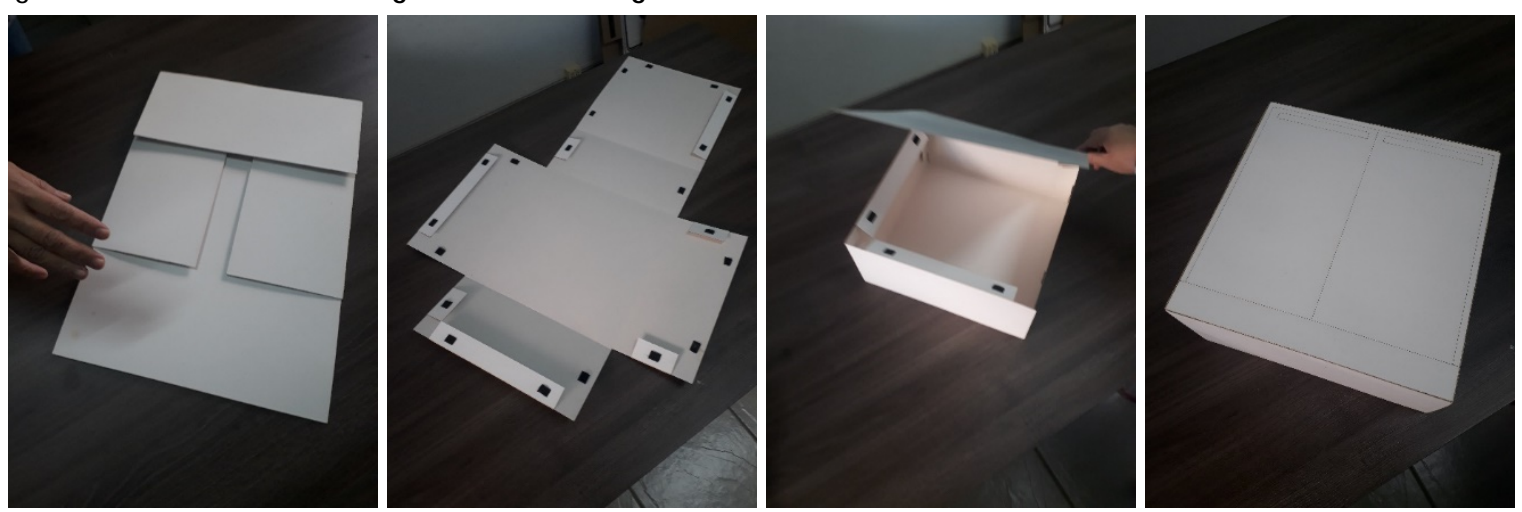

Figura 9 - Protótipo de equipamento executado na escala real em papelão ondulado

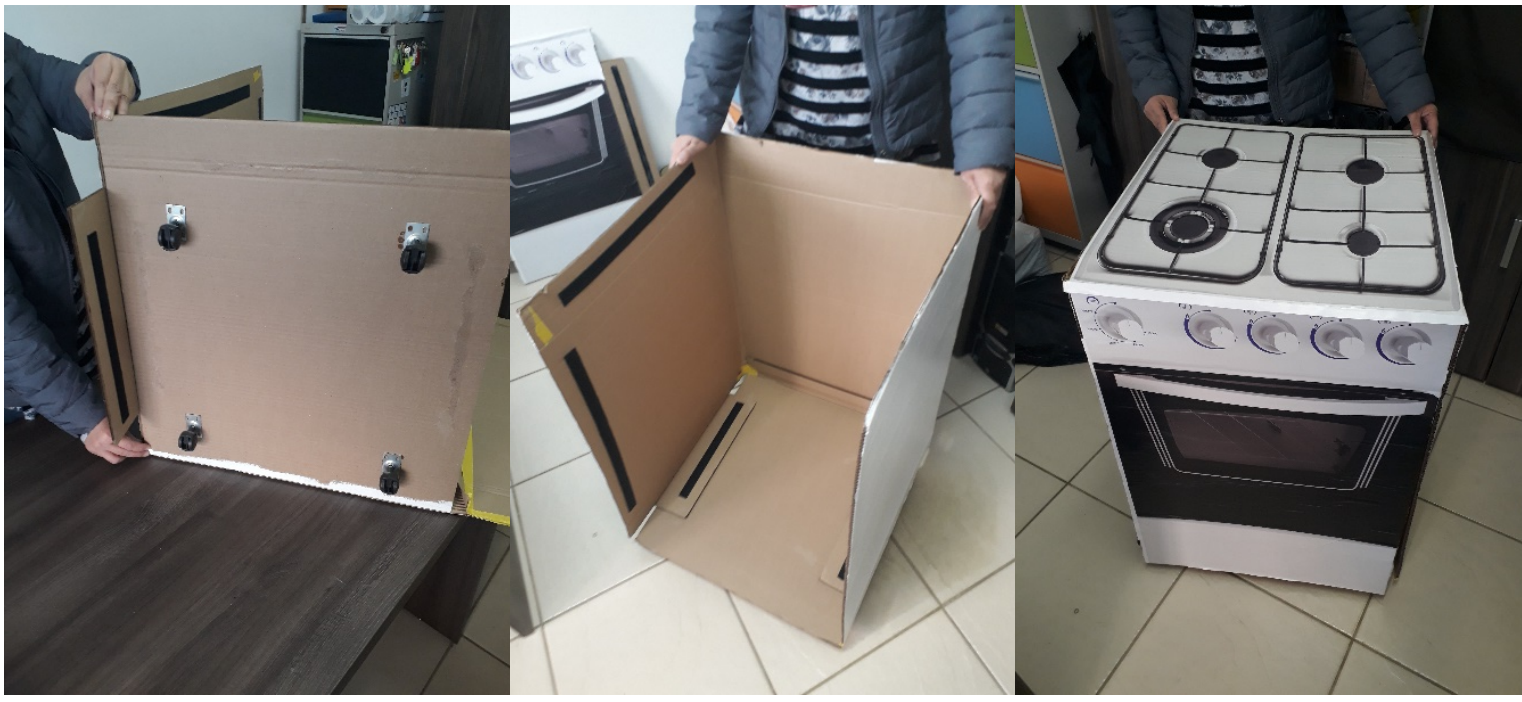


Figura 10 - Exemplos de simulação com o modelo (A)

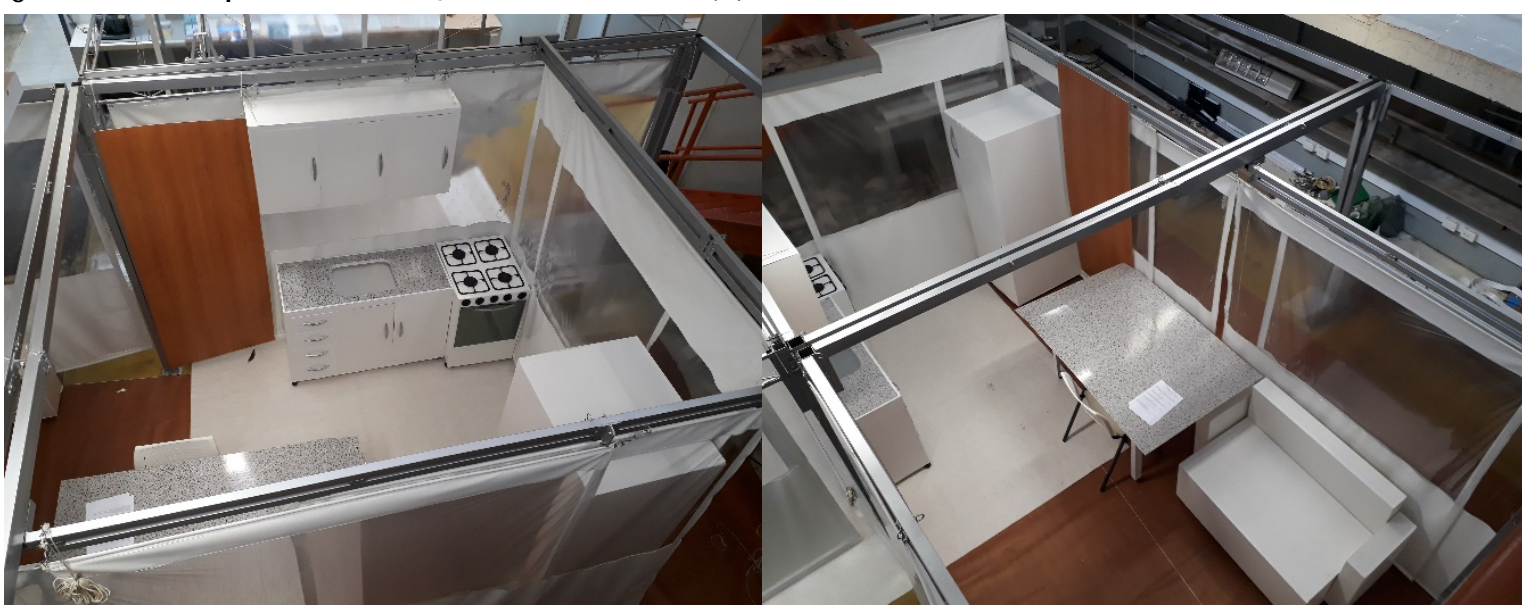

Figura 11 - Exemplos de leiaute utilizados como parâmetro

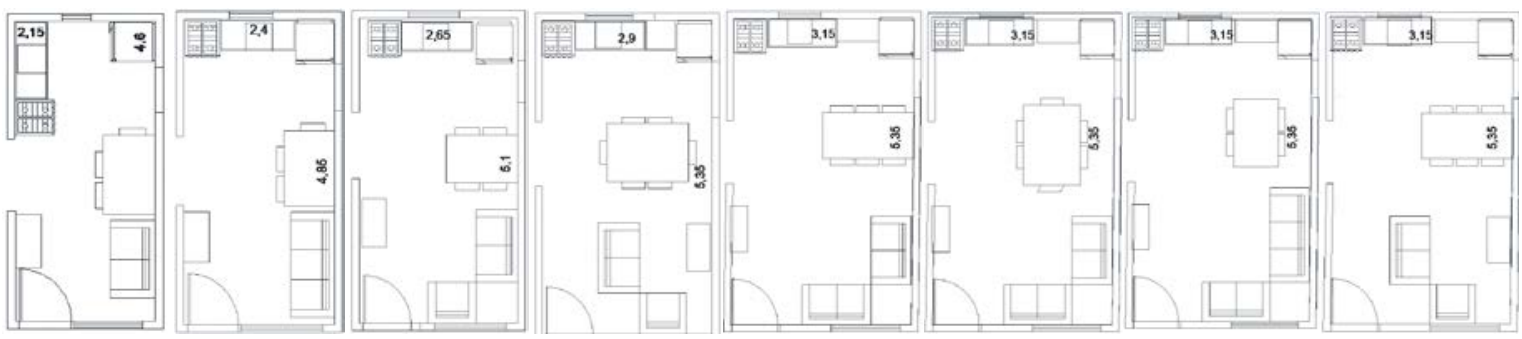

Após a definição desses parâmetros foi elaborado um roteiro de simulação a ser aplicado com alunos de uma disciplina de pós-graduação, compostos por profissionais formados em engenharia civil e arquitetura. Esses participantes tinham a faixa etária, em média, de 33 anos, com tempo de experiência na profissão de cerca de 11 anos, e pouco mais da metade atuam na área como projetistas, enquanto os demais estão mais na área acadêmica. Esse exercício foi desenvolvido no mês de outubro de 2018 e contou com a participação de 11 pessoas. O roteiro solicitava o desenvolvimento de alternativas projetuais baseadas em um leiaute com dimensões reduzidas que seriam gradativamente ampliadas conforme fossem modificadas as demandas espaciais (Figura 11). A meta dos participantes seria a discussão sobre questões como as recomendações de dimensões mínimas para móveis e equipamentos e aspectos de flexibilidade.

Após o exercício de simulação com os participantes foi realizado um questionário com o objetivo de avaliar o procedimento. As principais questões abordadas foram relativas à compreensão dos usuários sobre aspectos espaciais e funcionais dos três modelos empregados. Foram avaliadas questões como dimensionamento e quantidade de móveis e equipamentos, circulações e tamanho dos ambientes. Outros aspectos avaliados foram as eventuais mudanças de percepção espacial após a manipulação de cada modelo, a sua correlação com ambientes reais e se algum deles permitiu identificar questões que os outros não permitiram.

\section{Resultados: avaliação do artefato e comparação entre modelos físicos em diferentes escalas}

\section{Simulação ambiental com o modelo físico na escala 1:20}

A simulação de aspectos funcionais e ambientais de uma habitação hipotética, notadamente sala e cozinha, foram aplicados nas diferentes escalas dos instrumentos junto aos participantes da simulação, conforme relatado nos procedimentos. Para efeitos comparativos foi solicitado, a todos os participantes, respostas sobre questões relativas aos aspectos dimensionais e de leiaute dos espaços, considerando a avaliação a partir do modelo em escala 1:20. No quesito do tamanho dos móveis e equipamentos, houve relativa variação na percepção dos participantes, com maior tendência de avaliação de que esses móveis seriam maiores ou iguais ao que normalmente é utilizado em HIS (ver Figura 12). Como os padrões de dimensionamento utilizados para esses equipamentos foram os mesmos recomendados por manuais técnicos ou aqueles encontrados em 
lojas de mobiliário popular, pode-se inferir que a percepção variada em relação às dimensões deve-se a certa conformidade (ou não) dos participantes em relação a esses padrões. A percepção individual de que dimensões mínimas são uma consequência necessária derivada dos poucos recursos para a HIS e, portanto, inevitáveis como procedimento, pode ser contraposta a uma diferente percepção de que os padrões mínimos são insuficientes para gerar o conforto necessário. Essa discussão, baseada em percepções individuais, indica a necessidade de maior amostra de usuários para coleta de dados sobre esses dimensionamentos, pois, se essas dimensões são repetidas exaustivamente como parâmetros, elas indicam que podem resvalar em diferenças comportamentais e até antropomórficas que podem gerar insatisfações.

A quantidade de móveis empregados na simulação foi, para a maioria dos entrevistados, considerada como adequada (ver Figura 13). Houve a observação de um participante que indicou que a quantidade de móveis era insuficiente se comparada com a diversidade usualmente encontrada em pesquisas de avaliação pós-ocupação de HIS. Essa diversidade de móveis é derivada da própria diversidade cultural e comportamental desses moradores, que muitas vezes não necessariamente apenas compram esse material de lojas de móveis populares, mas que podem adquirir peças maiores, ganhar ou receber de presente ou ter acesso a peças usadas que não necessariamente são das dimensões mínimas recomendadas ou do padrão e diversidade previstos pelo projeto.

Os espaços entre móveis, assim como o tamanho, também tiveram certa diversidade de respostas, com maior tendência para avaliar as circulações como normais e grandes (ver Figura 14). Nesse quesito houve maior quantidade de respostas espontâneas em relação a essa percepção, principalmente quando comparadas com o modelo em escala real. Em linhas gerais houve a percepção de que o modelo em escala 1:20 proporcionava uma avaliação espacial que, quando confrontada com o modelo em escala real, era revista. No ambiente em escala real verificou-se que as mesmas circulações poderiam ser adequadas para determinados usuários e talvez não para outros. Também houve a percepção de que, no modelo reduzido, os espaços eram menores, o que não se confirmou no ambiente em tamanho real. Ou em outros casos, o que parecia adequado na escala reduzida foi considerado exagerado no tamanho real, como nos espaços de circulação entre diferentes móveis (sofás e mesas, por exemplo), consideradas circulações esporádicas.

Os tamanhos iniciais propostos para os ambientes da sala e da cozinha, de forma integrada, ainda que em setores diferentes do ambiente, foram considerados pequenos, sendo que alguns respondentes indicaram ser normais para essa tipologia (ver Figuras 15 e 16). O dimensionamento inicial proposto para a simulação dos ambientes foi de 2,15 m por 4,60 m (ver Figura 11), que seguiu as recomendações mínimas constantes na Norma NBR 15575-1 (ABNT, 2013) e de recomendações do Programa Minha Casa Minha Vida (MCMV). Posteriormente os ambientes foram sendo aumentados em suas dimensões e sendo solicitada a inserção de novos móveis.

Figura 12 - Avaliação em relação ao tamanho dos móveis na escala 1:20

\section{Tamanho móveis 1:20}

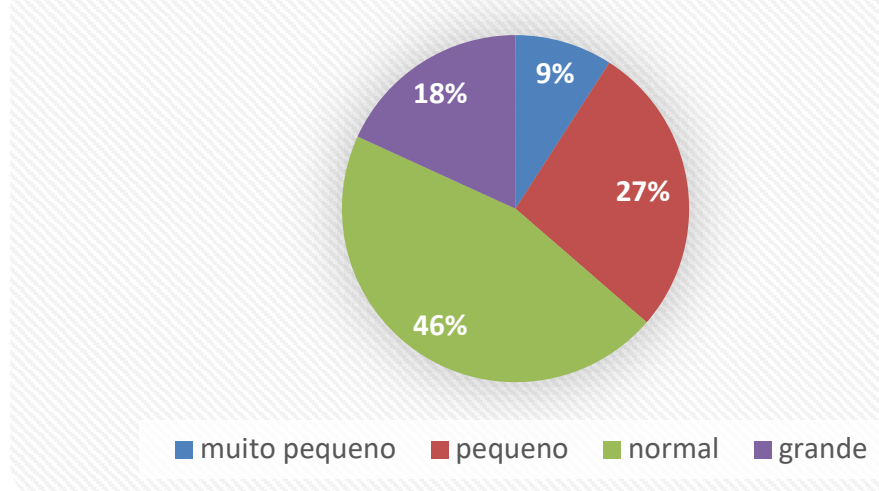


Figura 13 - Avaliação em relação à quantidade dos móveis na escala 1:20

\section{Quantidade móveis 1:20}

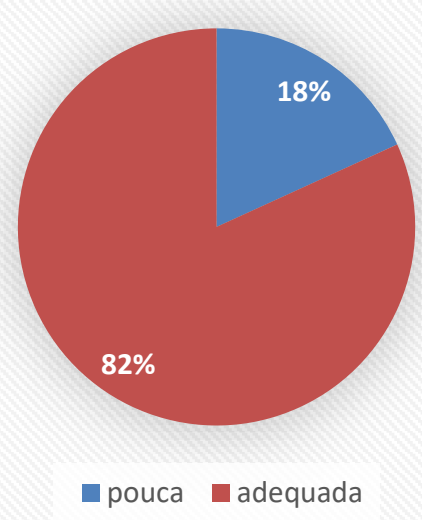

Figura 14 - Avaliação em relação ao espaço entre móveis na escala 1:20

\section{Espaço entre móveis 1:20}

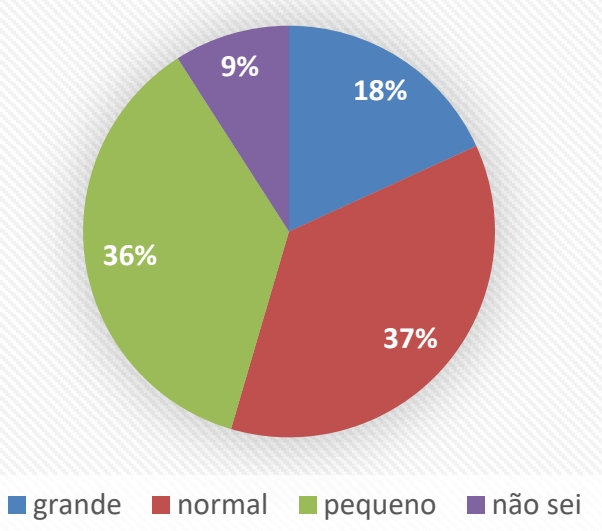

Figura 15 - Avaliação em relação ao tamanho da cozinha na escala 1:20

\section{Tamanho cozinha 1:20}

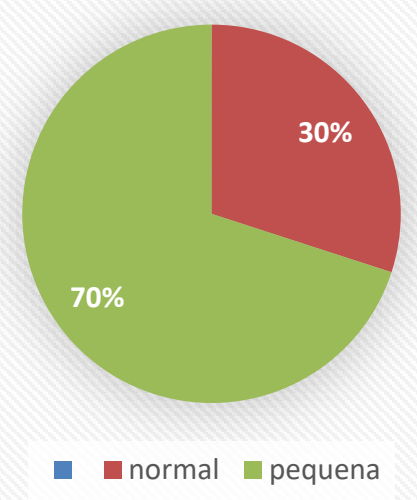


Figura 16 - Avaliação em relação ao tamanho da sala na escala 1:20

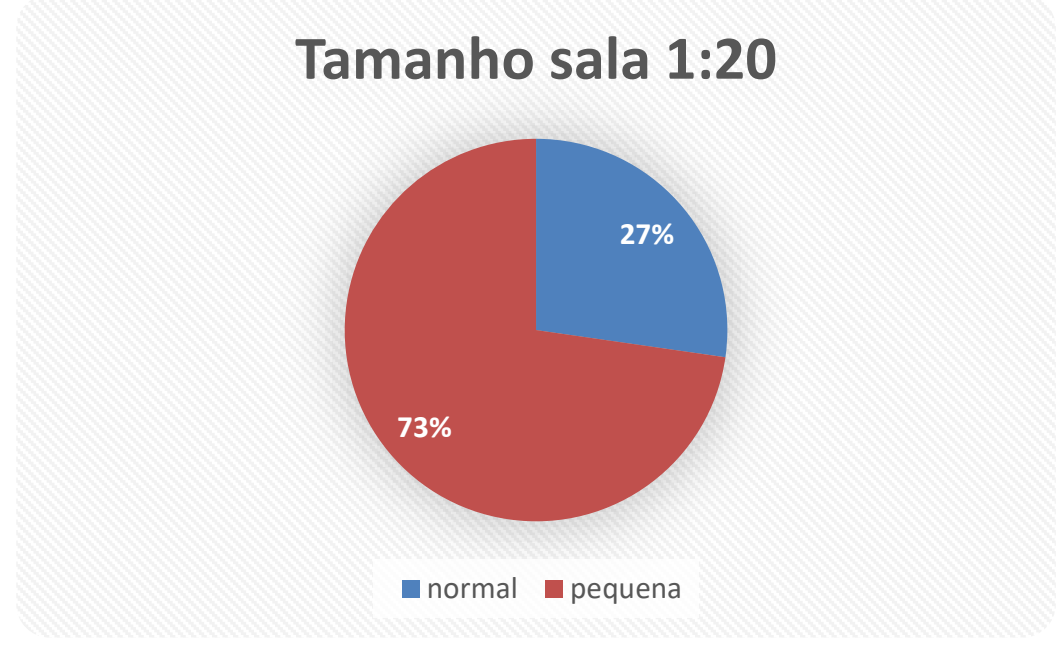

\section{Percepção ambiental e suas diferenças conforme a escala de representação}

Cerca de metade dos entrevistados (54\%) quando manusearam o modelo na escala 1:10 mantiveram a avaliação que tiveram da percepção do tamanho dos móveis quando utilizaram o modelo na escala 1:20, enquanto o restante teve uma nova percepção.

Os participantes que modificaram a compreensão dos ambientes ao manipular o modelo de maior escala indicaram que esse modelo dava a impressão de ser maior e incentivava a elaboração de maior quantidade de configurações de leiaute. Um dos respondentes indicou que o manuseio era facilitado pelas dimensões maiores do modelo e por um maior incremento de detalhes na representação. Uma das percepções da vantagem do aumento da escala foi de que a analogia com o ambiente real fica facilitada, pois se torna cada vez mais "parecido" com o objeto verdadeiro. O aumento do tamanho da escala, ainda que vantajoso em relação a esses aspectos, foi considerado inferior ao modelo na escala 1:20 na questão da visão do conjunto do projeto, justamente por sua menor dimensão.

Em relação ao tamanho dos ambientes, a maioria dos respondentes manteve a avaliação em ambas as escalas, com 64\% para a sala e 73\% para a cozinha. Como grande parte dos participantes indicaram que os ambientes eram pequenos na simulação com o modelo na escala 1:20, alguns desses mudaram de opinião quando manusearam o modelo na escala 1:10, confirmando que essa compreensão variou dependendo da escala de representação.

Em relação à quantidade de móveis (91\%) e à circulação entre móveis (82\%), a maioria dos respondentes manteve a avaliação da percepção que tiveram na escala 1:20, não havendo grande mudança nesses quesitos.

Essas variações de percepção entre duas escalas reduzidas de representação dos ambientes indicam que escalas maiores podem contribuir para ampliar a compreensão baseada em analogias com o ambiente real. O princípio de que quanto maior a representação, com a consequente ampliação dos detalhes do objeto representado, maior será a correlação e identificação com o objeto real, é reforçado quando analisamos os resultados da simulação com o modelo em escala real. Ainda que exista certa simplificação dos objetos, houve a intenção de que os ambientes e seus móveis tivessem representações similares, ainda que não idênticas. Esse procedimento ocorreu para não confundir a representação com um ambiente real, o que segundo Sommer e Sommer (1991) pode ampliar o stress e prejudicar os objetivos que se pretende alcançar no procedimento. A simulação em escala real tinha como objetivo permitir modificações no leiaute de forma simplificada e ágil, sendo os móveis executados com materiais leves e facilmente deslocados para diferentes posições durante o procedimento.

Quando comparamos a simulação com os modelos reduzidos e a simulação com a escala real, a maioria dos participantes indica que modificou a sua percepção em relação aos itens avaliados como no caso do tamanho dos móveis (91\%), da quantidade de móveis (54\%), da circulação (91\%) e do tamanho da sala e da cozinha (73\%). Ainda que em diferentes graus, conforme o item avaliado, houve uma ampla noção de que o ato de simular um ambiente físico em tamanho real permite maior sensibilidade e percepção da realidade.

Os comentários dos participantes indicam que o ato de caminhar no ambiente permite maior domínio dos espaços de circulação e do tamanho dos móveis. Nesse sentido, a percepção inicial nos modelos de que o 
projeto era "desconfortável” por suas dimensões reduzidas foi substituída pela sensação de que os espaços eram mais "aceitáveis" no tamanho real.

Outro aspecto identificado foi o de que o tamanho dos móveis e de seus espaços de circulação tiveram compreensões diferenciadas. Ainda que os modelos em escala reduzida indicassem as áreas necessárias para circulação, somente na simulação em tamanho real essas circulações ou sobreposições das áreas de utilização puderam ser mais bem avaliadas. A experiência da imersão física no interior dos ambientes, na simulação em escala real, causou a sensação de que a compreensão ambiental ficou "menos duvidosa e mais intuitiva para o usuário". Esse aspecto intuitivo é reforçado por um participante que indica que na escala real os dimensionamentos não são mais o aspecto referencial que eram nas escalas reduzidas. A percepção física e sensorial passa a ser o modelo referencial de avaliação, alterando a compreensão de aspectos que haviam sido identificados por analogias dimensionais em representações reduzidas. Nesse sentido, o que era percebido como pequeno pode ser identificado como grande e vice-versa. E que estar caminhando pelo ambiente, ainda que em um modelo de simulação, é "melhor" inclusive do que a realidade virtual e permitiria, por aspectos sensoriais e táteis, ter maior "poder de escolha" sobre as opções de projeto.

Em geral, os participantes das simulações avaliaram positivamente a compreensão ambiental que tiveram na experiência com o manuseio dos modelos. Ainda que em pequena proporção, houve um acréscimo na facilidade de entendimento das questões ambientais conforme as escalas são ampliadas. Em uma escala de valores que variava de 1 até 10 , a escala real teve a melhor avaliação, ainda que possuísse certa simplificação nos seus detalhes.

As diferentes escalas de representação, mais do que instrumentos concorrentes para explorar os aspectos do projeto em uma simulação, são ferramentas complementares que auxiliam em diferentes níveis de informação sobre questões ambientais. Outro aspecto identificado nos instrumentos é a sua característica didática e de compreensão de variadas questões do projeto. O Quadro 1 demostra as características e potencialidades de cada instrumento.

\section{Discussões}

A utilização conjunta de três artefatos similares, porém com diferentes escalas, possibilita uma visão mais ampla e geral quanto menor for o tamanho da representação. Conforme as escalas vão se ampliando, é possível revisar de forma crítica as soluções de projeto tomadas inicialmente, pois os detalhes permitem ampliar a compreensão espacial (ver Figura 17). Ainda que a visão do conjunto seja essencial para o planejamento do espaço, a partir do tamanho real os dimensionamentos de peças e circulações são mais bem compreendidos e analisados. Questões importantes como a geometria da solução de projeto, com seus alinhamentos das circulações, não são tão claras e perceptíveis no ambiente real, tendo a sua importância relativizada. A preocupação de uma composição geométrica, comum na visualização superior de plantas e de modelos, é substituída por uma noção mais geral de posicionamento das peças e circulações e por aspectos sensoriais de alcance corporal desses dimensionamentos. O corpo passa a ser a medida ambiental. Nas representações reduzidas, a analogia é feita por meio de comparações das dimensões dos móveis, das esquadrias ou de qualquer instrumento que permita a percepção da escala.

\section{Figura 17 - Avaliação da compreensão do ambiente conforme a escala de representação}

\section{Compreensão do ambiente conforme escala}

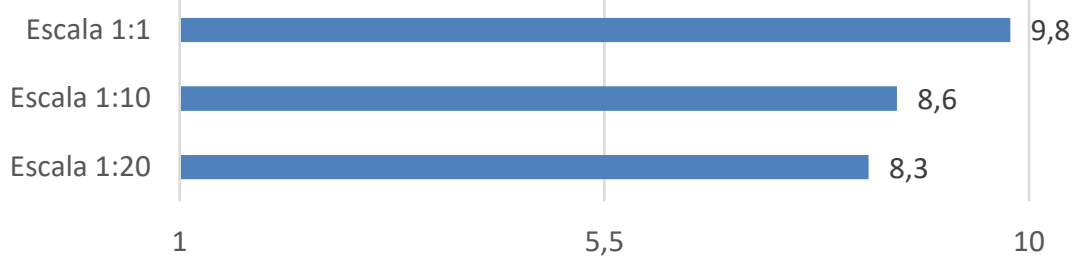


Quadro 1 - Aspectos de percepção espacial identificados nos modelos físicos

\begin{tabular}{|c|c|}
\hline MODELOS REDUZIDOS & MODELOS EM ESCALA REAL \\
\hline $\begin{array}{l}\text { Grande flexibilidade e agilidade na alteração do } \\
\text { leiaute }\end{array}$ & $\begin{array}{l}\text { Possui flexibilidade na alteração de leiaute, porém } \\
\text { de forma mais lenta devido ao tamanho das peças }\end{array}$ \\
\hline $\begin{array}{l}\text { Quanto menor a escala utilizada, maior a impressão } \\
\text { de que os móveis eram pequenos. Quanto maior a } \\
\text { escala, mais fácil a analogia com o ambiente real. }\end{array}$ & $\begin{array}{l}\text { O dimensionamento dos móveis, que eram } \\
\text { considerados pequenos, é percebido como mais } \\
\text { adequado quando visto em escala real }\end{array}$ \\
\hline $\begin{array}{l}\text { Dimensionamento das circulações identificado } \\
\text { como pequeno quanto menor a escala }\end{array}$ & $\begin{array}{l}\text { Maior percepção espacial em relação às } \\
\text { circulações, identificando detalhes relativos a } \\
\text { locomoção, atividades, prioridades e sobreposições }\end{array}$ \\
\hline $\begin{array}{l}\text { Dimensões mínimas dos ambientes, utilizadas em } \\
\text { HIS, são identificadas como mais insatisfatórias } \\
\text { quanto menor o modelo }\end{array}$ & $\begin{array}{l}\text { Percepção de que os ambientes eram maiores } \\
\text { quando visualizaram o modelo em escala real }\end{array}$ \\
\hline $\begin{array}{l}\text { Quanto menor a escala, melhor a percepção de } \\
\text { conjunto do projeto. Quanto maior a escala e os } \\
\text { detalhes representados, melhor a compreensão } \\
\text { espacial. }\end{array}$ & $\begin{array}{l}\text { Diminui a percepção do conjunto, focando no } \\
\text { posicionamento dos móveis e nas conexões de } \\
\text { atividades }\end{array}$ \\
\hline $\begin{array}{l}\text { Modelo foca em composições geométricas } \\
\text { espaciais de visualização aérea }\end{array}$ & $\begin{array}{l}\text { Modelo agrega qualidade na percepção por } \\
\text { aspectos sensoriais e ergonômicos, tendo o corpo } \\
\text { humano como medida ambiental }\end{array}$ \\
\hline $\begin{array}{l}\text { Maior limitação em simulações de atividades do } \\
\text { cotidiano }\end{array}$ & $\begin{array}{l}\text { Maior facilidade de simulação de atividades } \\
\text { levando em conta aspectos ergométricos e } \\
\text { antropométricos e de fluxos de usuários no mesmo } \\
\text { local e horário }\end{array}$ \\
\hline Maior facilidade no estudo de variações no projeto & $\begin{array}{l}\text { Necessita instrumentos complementares em escalas } \\
\text { reduzidas para estudar diferentes propostas de } \\
\text { projeto. Possui validade para conferir as propostas, } \\
\text { fazer mudanças e ajustes finos e verificar } \\
\text { alternativas. }\end{array}$ \\
\hline Discussão do projeto em suas etapas iniciais & Verificação de propostas \\
\hline $\begin{array}{l}\text { Instrumento focado na analogia por comparação e } \\
\text { na interatividade }\end{array}$ & $\begin{array}{l}\text { Instrumento focado no realismo, na sensorialidade } \\
\text { e na interatividade }\end{array}$ \\
\hline
\end{tabular}

Outro aspecto que diferencia a simulação entre diferentes escalas é a possibilidade de verificar as aberturas das portas dos móveis e equipamentos, como fogão, pia, geladeira e armários, por exemplo. Nesse caso, é possível simular atividades do cotidiano na escala real, ainda que com limitações, o que é muito mais difícil nas escalas reduzidas. O fato de estar imerso no ambiente também possibilita identificar questões ergométricas como altura de móveis, área de trabalho na cozinha e alcance para abertura e manuseio de portas e equipamentos, entre outras. Além desses aspectos, a simulação no tamanho real permite que várias pessoas interajam ao mesmo tempo no espaço, antevendo dificuldades nas atividades cotidianas em um grupo familiar.

Nas escalas reduzidas a dinâmica de estudar alternativas de projeto é mais ágil e rápida, o que permite explorar diversas possibilidades em um curto espaço de tempo. Na escala real, ainda que tenha sido planejada para ser leve e de fácil manuseio, o próprio dimensionamento torna o processo um pouco mais lento. Nesse caso, o tempo de exploração de alternativas leva a uma maior reflexão sobre as propostas. Cada instrumento demonstra ter um tempo próprio, que faz com que o processo tenha um caráter mais reflexivo, com maior prazo para ponderações, ou que seja mais ágil, explorando mais rapidamente diferentes alternativas e indo sistematicamente em busca de novas possibilidades.

Ainda que os modelos tridimensionais físicos tenham como proposta inicial permitir que usuários leigos participem da discussão sobre aspectos do projeto, em um processo participativo, o que seria mais difícil em instrumentos convencionais como uma planta baixa, o modelo em escala real possui uma similaridade com o ambiente que extrapola as representações tridimensionais ou bidimensionais. Basicamente, os modelos reduzidos permitem explorar alternativas de projeto e o modelo em escala real permite verificar essas alternativas e fazer ajustes em soluções pré-estabelecidas ou eventualmente o seu abandono em prol de um reinício do processo projetual. Conforme um dos participantes indica, o processo de simulação, como qualquer procedimento de antecipação de estados futuros não existentes, que basicamente é a função do projeto 
arquitetônico, dependerá da utilização de diferentes instrumentos que permitam captar diferentes informações: "Operar a escala real é menos dinâmico, mas mais realista e divertido. Foi interessante exercitar primeiro na maquete reduzida para entender o que não funciona”.

\section{Conclusões}

O uso de modelos físicos reduzidos para discussão sobre projetos é relativamente explorado por sua facilidade de manuseio e montagem quando comparado à execução de um ambiente real. Por esse motivo se prestam para discutir projetos em etapas iniciais ou para conferência dos resultados. Os modelos utilizados permitem certa flexibilização com tempo de manuseio relativamente rápido. No caso da escala real, ainda que planejado para simplificar o procedimento, demanda maior tempo de montagem prévia e para a própria simulação. Também não possibilita a montagem de ambientes mais complexos e amplos, pelo menos não com a característica de flexibilização pela mudança de posição de paredes, o que no caso dos modelos reduzidos demonstrou ser viável. O maior realismo e a interatividade na simulação em escala real permitem maiores discussões e reflexões sobre o ambiente que não seriam possíveis em outras representações.

A imersão, não apenas do usuário leigo, mas do próprio projetista, em um ambiente em escala real, abre possibilidades de reflexão sobre o projeto. Porém, essas possibilidades são tão mais complexas quanto maior for a dificuldade dos projetistas para se adaptar a uma nova forma de projetar, conforme relata um dos participantes da simulação. Os esquemas mentais do processo de projeto usual indicam um raciocínio abstrato derivado da experiência prévia do projetista e do domínio do conhecimento sobre a temática. Nesse sentido, a construção mental do objeto dependerá da capacidade individual do projetista e dos meios para representá-lo. Projetar o ambiente em escala real, com o suporte de soluções antecipadas em etapas prévias com instrumentos usuais, é uma diferente forma de abordagem do problema. Ainda que, provavelmente, não seja tão inovadora assim, mas possivelmente um retorno, com diferente abordagem, a um processo mais experimental e sensorial que já foi utilizado em períodos históricos antigos, com a diferença que as tecnologias digitais e de prototipagem permitem uma associação entre diferentes tipos de representações.

A forma de projetar utilizando esquemas de leiautes bidimensionais não foi substituída no momento em que os instrumentos digitais permitiram desenvolver os mesmos leiautes de forma tridimensional. Apenas as maneiras de pensamento projetual se mesclam e mudam a dinâmica de abstração do objeto no processo. O uso de um modelo em escala real traz um instrumento adicional de comunicação entre projetistas e usuários e pode abrir mais uma forma de verificação do projeto, com abordagem de questões ergonômicas e sensoriais de forma diferente ao usual e com ganhos de reflexão, análise e avaliação do processo e do produto final.

Espera-se, em trabalhos futuros, aplicar o artefato físico desenvolvido como forma de mediação de discussões e decisões em processos de projeto de HIS, envolvendo projetistas de arquitetura e usuários finais.

\section{Referências}

ASSOCIAÇÃO BRASILEIRA DE NORMAS TÉCNICAS. NBR 15575-1: edificações habitacionais: desempenho: requisitos gerais. Rio de Janeiro, 2013.

AZUMA, M. H. Customização em massa de projeto de Habitação de Interesse Social por meio de modelos físicos paramétricos. São Carlos, 2016. Tese (Arquitetura e Urbanismo) - Instituto de Arquitetura e Urbanismo, Universidade de São Paulo, São Carlos, 2016.

CELANI, M. G. C. et al. O processo de produção de uma maquete com técnicas de prototipagem digital. In: SIMPÓSIO NACIONAL DA GEOMETRIA DESCRITIVA E DESENHO TÉCNICO - GRAPHICA, 19., Bauru, 2009. Anais [...] Bauru: UNESP, 2009.

DRESCH, A.; LACERDA, D. P.; ANTUNES JÚNIOR, J. A. V. Design science research: método de pesquisa para avanço da ciência e tecnologia. Porto Alegre: Ed. Bookman, 2015.

GROAT, L.; WANG, D. Architectural research methods. $2^{\text {nd }}$. New Jersey: John Wiley \& Sons, 2013.

IMAI, C. et al. O modelo tridimensional físico como instrumento de simulação na habitação social. Gestão \& Tecnologia de Projetos, v. 10, p. 7-19, 2015.

IMAI, C. O sonho da moradia no projeto: o uso da maquete arquitetônica na simulação da habitação social. Maringá: EDUEM, 2010. 
IMAI, C.; AZUMA, M. H. A compreensão do objeto arquitetônico por meio do uso de prototipos tridimensionais: um estudo comparativo. In: GEOMETRIAS \& GRAPHICA, 2015. Proceedings [...] Porto: Aproged, 2015.

IMAI, C.; AZUMA, M. H. A evolução das maquetes como instrumento de representação e de comunicação na arquitetura. In: ENCONTRO TECNOLÓGICO DE ENGENHARIA CIVIL E ARQUITETURA, 7., Maringá, 2009. Anais. Maringá: UEM, 2009.

JENSEN, P. A.; ALEXANDER, K.; FRONCZEK-MUNTER, A. Towards an agenda for user-oriented research in the built environment. In: NORDIC Conference on Construction Economics and Organization: Shaping the Construction/Society Nexus. Proceedings. Aalborg: Danish Building Research Institute, 2011.

LAWSON, B. Como arquitetos e designers pensam. São Paulo: Oficina de textos, 2011.

MALARD, M. L. Avaliação Pós-Ocupação, participação de usuários e melhoria de qualidade de projetos habitacionais: uma abordagem fenomenológica. In: ABIKO, A. K.; ORNSTEIN, S. W. (org.). Inserção urbana e Avaliação Pós-Ocupação (APO) da Habitação de Interesse Social. São Paulo: Faculdade de Arquitetura e Urbanismo da Universidade de São Paulo, 2002.

PINA, S. A. M.; BORGES FILHO, F.; MARANGONI, R. F. Maquetes e modelos como estímulo à criatividade no projeto arquitetônico. In: KOWALTOWSKI, D. et al. (Org.). Processo de projeto em arquitetura: da teoria à tecnologia. São Paulo: Oficina de Textos, 2011.

RODRIGUES, Rodrigo. A simulação como ferramenta para a identificação dos requisitos dos usuários idosos na habitação. Londrina, 2016. Dissertação (Mestrado em Arquitetura e Urbanismo) - Escola de Arquitetura, Universidade Estadual de Londrina, Londrina, 2016.

SANDERS, E. B.; STAPPERS, P. J. CoCreation and the new landscapes of design. CoDesign: International Journal of CoCreation in Design and the Arts, v. 4, p. 5-8, 2008.

SANDERS, E. Prototyping for the design spaces of the future. In: VALENTINE, L. Prototype: design and craft in the 21st century. London: Bloomsbury, 2013.

SANOFF, H. Community design: a new delivery system. In: 53 RESEARCH papers in social architecture: 1965-2005. Raleigh, Aardvark, 2006a.

SANOFF, H. Community participation methods in design and planning. New York: John Willey \& Sons, 2000.

SANOFF, H. Democratizing design and planning through community participation. In: 53 RESEARCH papers in social architecture: 1965-2005. Raleigh, Aardvark, 2006b.

SOMMER, R.; SOMMER, B. A practical guide to behavioral research, tools and techniques. New York: Oxford University Press, 1991.

WANG, D. Simulation Research. In: GROAT, L.; WANG, D. Architectural research methods. $2^{\text {nd. }}$ ed. New York: John Wiley \& Sons, 2013.

ZALITE, M. G. A. Prioridades (declaradas) dos usuários para o projeto da habitação de interesse social identificadas por meio de simulação com modelo físico. Londrina, 2016. Dissertação (Mestrado em Arquitetura e Urbanismo) - Escola d eEngenharia, Universidade Estadual de Londrina, Londrina, 2016.

\section{Agradecimentos}

Os autores agradecem à Fundação Araucária pelo auxílio à pesquisa utilizado na montagem do artefato; à CAPES pela bolsa de pós-doutorado para realização da pesquisa e ao CNPq pela bolsa de produtividade em pesquisa Processo 306998/2018-1. 


\section{César Imai}

Departamento de Arquitetura e Urbanismo | Universidade Estadual de Londrina | Rodovia Celso Garcia Cid, PR 445 Km 380 | Londrina PR - Brasil | CEP 86.057-970 | Tel.: (43) 3371-4535 | E-Mail: cimai@uel.br

\section{Márcio Minto Fabricio}

Instituto de Arquitetura e Urbanismo | Universidade de São Paulo | Av. Trabalhador São Carlos, 4000 | São Carlos - SP - Brasil | CEP 13566-590 | Tel.: (16) 3373-9279 | E-Mail: marcio@sc.usp.br

\section{Ambiente Construído}

Revista da Associação Nacional de Tecnologia do Ambiente Construído

Av. Osvaldo Aranha, 99 - 30 andar, Centro

Porto Alegre - RS - Brasil

CEP 90035-190

Telefone: +55 (51) 3308-4084

Fax: +55 (51) 3308-4054

www. seer. ufrgs. br/ ambienteconstruido

E-mail: ambienteconstruido@ufrgs.br

This is an open-access article distributed under the terms of the Creative Commons Attribution License. 